\title{
KNOWLEDGE SHARING AMONG HEALTHCARE WORKERS IN MULTICULTURAL ENVIRONMENTS
}

Kimberly Scott, Keiser University, Ft. Lauderdale, Florida, U.S.A. Borivoje-Boris Djokic, Keiser University, Ft. Lauderdale, Florida, U.S.A.

dx.doi.org/10.18374/JIBE-20-1.1

\begin{abstract}
Tacit or explicit knowledge is viewed as one of the most valuable resources in any multicultural organization. The sharing of knowledge helps organizations increase competition, identify efficient work procedures, access information quickly, and reduce time investments for employees to learn new concepts or build on the existing foundation. The structure of any health care organization shows great diversity, ranging from administrators to health care employees to patients. Researchers have found that the most critical reason for mistakes in the hospital is a lack of knowledge and experience. Therefore, knowledge sharing is essential in the health care field due to the number of individuals who depend on the information. Members of health care organizations need to be as agile and intelligent as possible, and one way to meet the necessity is to enable members to share their knowledge efficiently in any venue necessary. The purpose of the current quantitative correlational study was to investigate the impact of knowledge sharing between national cultures focusing on health care workers in the United States and Egypt. The study was used to examine the factors affecting the willingness to share information in 4 subareas.
\end{abstract}

Keywords: Knowledge, Knowledge Sharing, National Culture, Multicultural, Sharing Culture 